\title{
Editorial
}

\section{Leadership and the Humanities: un an après}

In Vingt Ans Après (Twenty Years After), Alexandre Dumas tells about the reunion of the three musketeers with D'Artagnan, in order to protect young King Louis XIV (Le Roi Soleil - The Sun King) and the doomed Charles I from their attackers. They were very tough times: the novel follows tragic events in France during La Fronde, during the childhood reign of Louis XIV, and in England near the end of the English Civil War, leading up to the victory of Oliver Cromwell and the execution of King Charles I. A characteristic of such a novel is that its author comes out on the side of the monarchy in general, or at least that the text often praises the idea of benevolent royalty.

The times in which we currently live are equally turbulent: Europe is experiencing its first political and economic crisis as a global community; corruption is exploding in every part of the world; despair (in the Mediterranean with the massacre of migrants from Syria and Africa) and war (in Ukraine) are just round the corner; and famine has not disappeared. Totalitarian winds are blowing from everywhere. It seems, however, that there is a lack of genuine leadership at every level; and that dominant social sciences leadership paradigms are in trouble or have even failed if they have not been integrated with lessons from other disciplines (Riggio 2011). In other words, we are living in a time similar to that in which Dumas was writing his novel: a turbulent age in which hegemonic culture in each field is indifferent to its methodological problems and its challenged outcomes. Yet mainstream social science leadership studies claims for itself an undisputed role as much as the Sun King claimed during the times in which Dumas's novel took place.

Leadership and the Humanities crossed the finish line of its first year. We would like to offer some reflections triggered by the submissions we have received so far. They raise considerations on the interdisciplinary nature of leadership studies and on what I would call the 'methodological problem' (others have called it the 'definition problem'). Before addressing those problems, I will disclose some facts about the journal.

\section{SOME FACTS ABOUT THE JOURNAL}

Since August 2012 to December 2013, Leadership and the Humanities received 56 papers. Submissions accepted for publication were only 12 (including this issue). Therefore the overall mortality rate for papers is about 79 percent: one out of every five papers submitted was good enough for publication in LATH. While the rate would seem impressive, it is something we did not choose; it is, rather, an outcome of the kind of papers submitted. Contrary to the journal mission, stated explicitly in the journal and on our webpage, most submitted papers nevertheless had a mainstream social science focus, and were not the kind of papers we were seeking. The majority of 
the rejections were due to the fact that the authors likely thought of $L A T H$ as a journal that arose in the wake of the most famous academic journals in the field (namely Leadership Studies Quarterly, Journal of Leadership Studies, and Leadership). Indeed, we rejected some very sophisticated papers containing large sets of data, regardless of whether they were analysed under (old or new) qualitative or quantitative methodologies. Our purpose was not to be a pale replica of those leading journals, but a brand new, vibrant, and challenging forum in which scholars with a humanities-focused mind would offer their research, thoughts, and intuitions to leadership studies as an emerging discipline.

It is worth noting that the number of submissions with a social science focus has decreased since the beginning of 2014. What does this mean? After a year, it is likely LATH made its positioning clear within the roster of leadership journals by publishing high quality papers, humanities-related. No compromises for the sake of publishing were made.

Such successful inspiration - after much internal debate - is owed to Thomas J. Wren (former $L A T H$ co-editor), who made a fundamental contribution to the journal's identitybuilding. Tom, as we usually name him, was a kind of compass for the journal. From his many years of experience, it was he who explained to us how to orient ourselves within the vast landscape of leadership studies. Tom has now retired, but has promised to provide detached yet continuous help with our endeavor to keep the journal lively. We are deeply grateful to Tom for his suggestions and support.

\section{THE INTERDISCIPLINARY NATURE OF LEADERSHIP STUDIES}

According to Riggio (2011), leadership studies is an emerging discipline, and he states: 'I have every expectation that a generation from now leadership studies will be a recognized discipline and universities that do not have departments of leadership studies (or at least programs devoted to leadership) will be a minority' (ibid., p. 9). Riggio then starts examining a bunch of theories regarding the very notion of 'academic discipline.' Interestingly, he examines the so called paradigm development approach as discussed by Thomas Kuhn (1962) in his famous and frequently cited book on scientific revolutions. Riggio makes a huge effort in explaining that leadership studies possesses many of the formal elements of an emerging discipline (journals, places of discussion such as conferences, websites, and blogs, Library of Congress recognition, etc.) but does not talk about intra-disciplinary problems, including an excursus on how interdisciplinary fields become a new discipline. I will now say something more about this aspect, as it is intimately related not only to the interdisciplinary nature of leadership studies but also to future development within the discipline.

Apparently new disciplines stem from old disciplines (such as philosophy), or they are the result of a coagulation of different disciplines around a particular paradigm. While it is undisputed that Leadership has its conceptual roots in Greek philosophy (usually we refer to Plato's Republic, Plutarch's Lives, or Aristotle's Nichomachean Ethics as the very first books in which the leadership phenomenon is analysed), it is somewhat difficult to find a continuity (as occurs in some empirical sciences) between those writings and contemporary leadership studies. The term 'Leadership' is indeed a relatively recent term (it emerges in the English language around the fourteenth century), and for this reason ancient leadership writings cannot be fully related with modern academic terminology; 
in Kuhn's own terms they are incommensurable: ${ }^{1}$ there are fractures in the history of leadership studies that make old taxonomies in the discipline untranslatable into the lexicon that is actually available to leadership scholars.

We should turn our eyes to the more homogeneous contemporary field of leadership studies and focus our gaze on the interdisciplinary nature of the field. Coagulation of several approaches around a common paradigm is a normal trend when we look at the development of some sciences. Molecular biology started its development by attracting scholars from several disciplines: theoretical physics, medicine, biology, computer sciences, mathematics, and so on. Scholars agreed around a peculiar paradigm such as the DNA double-helix structure and what is called the central dogma of molecular biology. ${ }^{2}$ Once agreeing around a paradigm, scholars create a disciplinary identity and no established field can claim the primacy of the new one. This is one of the problems Riggio sees as a resistance to the establishment of leadership as a discipline. As he states, 'several established disciplines claim leadership as their own - psychology, management, and, surprisingly, some in political sciences' (Riggio 2011, p. 16). The reason for their claims is not analysed by Riggio. ${ }^{3}$

By contrast, Artificial Intelligence - another famously multidisciplinary field - did not find a paradigm around which those interested in the field could agree: failure of the Strong Artificial Intelligence paradigm and the subsequent failure of the Weak Artificial Intelligence paradigm (famously proposed in Searle 1980) led to a disciplinary abortion. As a result, Artificial Intelligence was absorbed into the field of Cognitive Sciences, while at the same time fragmenting into a myriad of tiny hyper-specialized sectors (such as planning and problem solving, synthetic intelligence, nanotechnology, etc.).

Different disciplines have different aims, definitions, and objects, and often different methodologies. No surprise that they tend to claim primacy on Leadership Studies. On the other hand, scholars interested in Leadership Studies should start a serious and collaborative debate over its disciplinary foundations if they wish Leadership Studies to follow the same path as Molecular Biology and become a true, established discipline. This is one of the reasons this journal was created.

\section{THE METHODOLOGICAL PROBLEM}

Here we reach another core problem affecting Leadership Studies, namely the 'methodological problem.' This term means a series of problems that are - from a methodological point of view - barely touched by leadership academics and scholars, with the notable

1. According to Oberheim (2005, p. 365), 'Kuhn initially used the term holistically to capture methodological, observational and conceptual disparities between successive scientific paradigms that he had encountered in his historical investigations into the development of the natural sciences (Kuhn 1962, 148-150). Later, he refined the idea arguing that incommensurability is due to differences in the taxonomic structures of successive scientific theories and neighbouring contemporaneous sub-disciplines.'

2. The central dogma of molecular biology is an explanation of the flow of genetic information within a biological system. It was first stated by Francis Crick in 1958 and re-stated in a Nature paper published in 1970.

3. Riggio (2011, p. 12) claims that ' $[w]$ hile there is not a general theory of leadership, there are constructs, such as charismatic leadership, systematic classifications of leader behavior, and interactionist models of leadership, that have been widely and thoroughly researched, some for nearly 100 years.' 
exception of those with a philosophical education. The definition of the problem is the most known: what is leadership? What is a leader? Are we talking leadership from an ideal point of view or from a real point of view? From such fundamental questions stems another subset of foundational problems: how much weight should we give to leadership structures and personal leadership within Leadership Studies? In other words, is it more important to understand the structures of leadership than how to develop a leader? Do problems of democracy and egalitarianism in an organization have priority over the understanding of leaderful characteristics?

Another bunch of issues are related to the vast folk literature on leadership which has caught the attention of the general audience (Riggio (2011, p. 17) refers to them as a 'plethora of popular trade books') and in some cases are able to influence not only leadership practice but also leadership theory. Here I refer to bestsellers describing how some leaders happened to be leaders, or books written by disciplinary gurus. As many authors have underlined (for instance, see Gosling and Marturano 2005) in most of their popular books, authors start talking about how a leader actually performs and then imply that to be a successful leader you have to perform in much the same way. This implication, far from being clear-cut, is something of a logical or methodological hazard. The implication can be paralleled with the so-called Hume's Law (or Hume's guillotine), which famously warns about shifting from descriptive to normative. Inferring a normative sentence from a descriptive sentence is, according to David Hume, a fallacious move. Hume discusses the problem in book III, part I, section I of his book, A Treatise of Human Nature (1739 [2000]):

In every system of morality, which I have hitherto met with, I have always remarked, that the author proceeds for some time in the ordinary way of reasoning, and establishes the being of a God, or makes observations concerning human affairs; when of a sudden I am surprised to find, that instead of the usual copulations of propositions, is, and is not, I meet with no proposition that is not connected with an ought, or an ought not. This change is imperceptible; but is, however, of the last consequence. For as this ought, or ought not, expresses some new relation or affirmation, it is necessary that it should be observed and explained; and at the same time that a reason should be given, for what seems altogether inconceivable, how this new relation can be a deduction from others, which are entirely different from it. But as authors do not commonly use this precaution, I shall presume to recommend it to the readers; and am persuaded, that this small attention would subvert all the vulgar systems of morality, and let us see, that the distinction of vice and virtue is not founded merely on the relations of objects, nor is perceived by reason.

Related to this problem is the normative/descriptive problem in Leadership; Joanne Ciulla famously developed this issue carefully in her seminal paper 'Leadership Ethics: Mapping the Territory' (Ciulla 1995).

Many observed that Leadership Studies is a leader-centered discipline. Scholars are more interested in leadership development than in structures of leadership conceived as a system of relations within an organization: on the one hand there is a leader and on the other hand there are followers; and according to the famous Peter Drucker (2001, p. 271) statement, 'The only definition of a leader is someone who has followers.' Scholars (but not only they) have interpreted such statements as if substantial research into the ideal characteristics of leaders (that is, characteristics aimed at impressing and catching followers) would be the mainstream way to study Leadership. At the beginning of the Renaissance, astronomy and theology started detaching from each other; as a result, cosmology - that is, the study of the material structure and laws that govern the universe, conceived as an ordered set - has changed. Ptolemy in his 
Almagest created such a Cosmological Order by using ancient Greek writings. Roughly speaking, according to cosmology, there was a strict correspondence between astronomic order and human hierarchies. In this ordered set, humankind has a central place in the universe (as much as a leader has a central place in the 'leadership cosmology'). Copernicus, to the contrary, formulated a heliocentric model of the universe which placed the Sun, rather than the Earth, at the center. The Copernican Revolution has collapsed the mainstream cosmology in which humankind was not at the center of the universe; such a revolution changed the hegemonic cultural weltanschauung, triggering the Renaissance, which, with Galilei's works, has removed the solar system from its centrality in the universe by putting it on a par with countless other systems in the galaxy. During the Renaissance, the subsequent cosmological dethronement of humankind from a central place in the universe led first to a sense of bewilderment in common sense, but later triggered new and more fruitful paradigms in science, art, and literature. In a similar way, it would be interesting to explore whether studies on leadership - placing leaders as a central concept - would shift to the study on followers. Furthermore, leadership-followership relationships should be studied as one of the possible worlds in which such particular relationships may exist, putting emphasis on the complexity and co-existence of all the possible leader-follower relations in an organizational universe. At the end of the day, followers create a leader first, and then a leader should help followers to rise to the leadership level: this is possible only if leaders are selected by followers whose cultural habit is not driven by mere basic needs or selfish impulses, but from a mutual process that emphasizes higher content and long-term goals.

My previous remarks are a proposed humanities point of view agenda for Leadership Studies; a list of issues that would be welcomed as themes for future submissions to this journal, aimed at challenging mainstream research in Leadership Studies yet widening the philosophical or metatheoretical basis of the discipline.

\section{PREVIEW OF THIS ISSUE'S ATTRACTIONS}

Along the lines described above, Jon Aarum Andersen in this issue addresses a methodological problem regarding the neglected distinction between managerial and political leadership, which is in literature is often conflated. The argument here is that leader, subordinates, and tasks are the properties that must exist for managerial leadership to exist. Political leadership, Andersen claims, contains the properties of leader, leader's goals, and followers. The political leadership concept, the author argues, does not specify any tasks assigned to the followers. Linked to this, claims Andersen, there is a foundational problem to change leadership into philosophical questions, as many leadership questions are infact ontological or epistemological problems.

Mark H. McVay's paper describes Eugene V. Debs's theory of discursive resistance within the Greenleaf servant-leader paradigm. Debs was an American union leader, one of the founding members of the Industrial Workers of the World, and five times the Socialist Party of America's candidate for President of the United States. Through his presidential candidacies, as well as his work with labor movements, Debs eventually became one of the best-known socialists living in the United States. Discursive resistance is a poststructuralist tactic that allows a leader to capitalize on the foundational beliefs of a culture or organization that form the basis for the prevailing narrative the leader seeks to contest. The leader's alternative narrative may be utilized to challenge and perhaps defeat the prevailing discourse by exposing its contradictions and 
demonstrating that the new alternative discourse is really more consistent with the foundational beliefs of the culture or organization the leader is operating within. Looking at Debs's words through a poststructural lens, according to McVay, allows us the privilege of another perspective on an important progressive American leader. This lens, the author claims, clarifies how leaders might utilize the tool of discursive resistance to change a dominant and oppressive narrative.

A quite contested concept today is that of Privacy. In an era of global and pervasive communication, it's difficult to defend someone's privacy as many institutions are interested in getting the most intimate and yet profitable data on an individual. In Terry L. Price's paper, his main concern is with privacy claims that individuals have against other individuals. The focus of the author's argument is on potential claims a leader might make to privacy. Moreover, the claims Price has in mind are not legal claims but, rather, moral appeals to the value of autonomy. Finally, the context for his argument is political leadership - although, as we shall see, his conclusions have implications for leadership in other contexts as well. Price claims that autonomybased arguments for privacy do not apply with the same force in leadership contexts and, in fact, that they go in the opposite direction. By this claim, the author means that the value of autonomy does not support leaders' appeals to privacy; instead, the autonomous choices of leaders (and followers) serve as the moral grounds for reductions in leader privacy. To make this argument, Mill's analysis in On Liberty is considered. Could this be applied in leadership contexts to derive some special privacy protection for leaders? Price concludes that such an application ultimately fails. It does so because it ignores the special obligations that leaders have to followers and the ways in which private behavior can impede leaders' ability to discharge these obligations.

In a new section entitled 'Poets on Poets', we are honored to offer the thoughts on leadership of Jehanne Dubrow, one of the most important and prolific American poets and the winner of the Washington Writers' Poetry Competition in 2009. She takes her cue from two-time Pulitzer recipient Richard Wilbur's political poem, 'For the Student Strikers.' This poem was written in 1970, when students at Wesleyan University were boycotting classes in protest at the war and canvassing the neighboring city of Middleton, Connecticut — not then a particularly anti-war community. The leadership lesson we can get from that poem, according to Dubrow, is that the strikers are urged to listen to others, to empathize with those who are different, and to recognize the humanity in the opposition. Michael Harvey provides a lucid and thoughtful introduction to Dubrow's piece.

Finally, Chrysavgi Sklaveniti reviews Doris Schedlitzki and Gareth Edwards's 2014 book, Studying Leadership: Traditional and Critical Approaches. The book is grounded in the authors' interest in provoking critical thinking in the study of leadership. Their aim is not only to present leadership, but also to recognize different theoretical, methodological, and geographical positions. In doing so, their readers are introduced to a clear message: to study leadership critically and apply their thinking in practice. The target audience for the book is leadership students and leadership educators. According to its reviewer, the complex field of leadership from a multitude of perspectives is presented successfully in the book; indeed, for students, the book is an efficient introduction to the main topics and dilemmas in leadership, while for educators it is a valid guide that will initiate the conversation with students about leadership without imposing a particular perspective or agenda. 
I believe that, once again, this issue of Leadership and the Humanities is successful in providing a rich variety of contributions to all readers interested in new and fresh ideas in the field.

Antonio Marturano

\section{REFERENCES}

Ciulla, J. (1995), 'Leadership Ethics: Mapping the Territory,' Business Ethics Quarterly, 5(1), 5-24. Drucker, P. (2001), 'Leadership as Work,' in The Essential Drucker, New York, NY: Harper Business, pp. 268-271.

Gosling, J. and Marturano, A. (2005), 'Editorial,' Business Ethics: A European Review, 14(4), 319-322.

Hume, D. (1739 [2000]), A Treatise of Human Nature, D.F. Norton and M.J. Norton (Eds), Oxford, UK: Oxford University Press.

Kuhn, T.S. (1962), The Structure of Scientific Revolutions, Chicago, IL: University of Chicago Press.

Oberheim, E. (2005), 'On the Historical Origins of the Contemporary Notion of Incommensurability: Paul Feyerabend's Assault on Conceptual Conservativism,' Studies in the History and Philosophy of Science, 36, 363-390.

Riggio, R.E. (2011), 'Is Leadership Studies a Discipline?', in M. Harvey and R.E. Riggio (Eds), Leadership Studies: The Dialogue of Disciplines, Cheltenham, UK and Northampton, MA: Edward Elgar, pp. 9-19.

Searle, J.R. (1980), 'Minds, Brains and Programs,' The Behavioral and Brain Sciences, 3, 417-457. 